\title{
Nutrition and Health
}

T

WO years ago the League of Nations set up a Mixed Committee on the Problem of Nutrition, consisting of agricultural, economic and health experts, and including representatives of the Advisory Committee on Social Questions, the International Labour Organisation and the International Institute of Agriculture. An interim report was published more than a year ago, in four volumes : the report proper, a report on the physiological bases of nutrition, and volumes entitled "Nutrition in Various Countries" and "Statistics of Food Production, Consumption and Prices", the latter being compiled by the International Institute of Agriculture, Rome. The interim report was devoted primarily to explaining the new conceptions which, in the opinion of scientific investigators, should govern human nutrition, to showing the effects of disregarding these rules, and to framing recommendations which might form the guiding principles of national nutrition policies. The economic and agricultural aspects of the problem, briefly referred to in the interim report, were reserved for further treatment, and the final report, which has now been published*, is primarily concerned with them.

The report is divided into three parts: the first, which has three chapters, describes the activities of the Mixed Committee and of other international bodies working on the problem of nutrition, outlines the general trend of progress in nutrition and public health during the past century, and finally summarizes the contents and conclusions, reproducing also the recommendations published in the interim report. The second part is devoted exclusively to the health aspect of nutrition, and reproduces, with such minor modifications as recent research has made necessary, the section of the interim report dealing with nutrition and health. The third part, which constitutes the bulk of the report, deals with the economic and agricultural aspects of the nutrition problem : in its seven chapters the recent tendencies in foodconsumption habits and in agricultural production are traced, the problem of food prices and the role of income in determining nutritional levels are analysed, and the part which education can play in determining food habits is considered: finally, a chapter is devoted to showing that in spite of the gradual improvement in nutrition which has taken

* Nutrition. Final Report of the Mixed Committee of the League of Nations on the Relation of Nutrition to Health, Agriculture and Economic Policy. (Official No. : A. 13, 1937, II, A.) Pp. 327. (Geneva : League of Nations; London: George Allen and Unwin, Ltd., 1937.) 7s. $6 d$. place in recent decades, malnutrition still exists in all countries, even in those with the highest general plane of living. The report is mainly concerned with conditions in Europe and countries with a Western civilization, since the Committee found that it would not be possible, in the time at its disposal, to obtain adequate documentation of conditions in the Far East; the Health Organisation is, however, taking measures to promote a full consideration of the problem of nutrition in this part of the world.

The advance in our knowledge of the principles of correct nutrition makes it possible to lay down with some precision what is an adequate diet in different circumstances. The report divides foodstuffs into two classes : (1) the protective foods, such as milk, glandular animal tissues, eggs, 'fat' fish, green vegetables and fresh fruit, which provide minerals, vitamins and 'good' (or animal) protein ; and (2) the energy-bearing foods, such as fats, cereals and sugar. The basic figure for the energy requirement of the average adult, male or female, living an ordinary everyday life in a temperate climate and not engaged in manual work, is fixed at 2,400 calories net (that is, after deducting waste in cooking and at table) per day. It is suggested that 1,400 calories should be obtained from protective foods, and the use of highly milled cereals and an excessive amount of sugar in the diet is deprecated: special attention is directed to the value of the potato as a food rich in calories and in starch, which is particularly suited as a substitute for sugar and cereals in the modern European diet. Among the protective foods special emphasis is laid on the need for milk in the human dietary and on the value of fish liver oils as supplements for their content in vitamins $\mathrm{A}$ and $\mathrm{D}$.

The report directs attention to the improvement in nutrition and public health during the past century, owing to the improvements in economic welfare and sanitation and to the advances in medical knowledge, and presents statistics to show that in all Western countries the average diet of the population has become increasingly diversified during recent decades, with a definite tendency, stronger in some countries than in others, but everywhere present, for the consumption of protective foods to increase, and for that of the purely energy-bearing foods, such as cereals and potatoes, to decrease. The changing content of the diet is not an accident : it corresponds to a genuine change both in physiological requirements and in the power to satisfy them. 
The principal cause is the reduction in the expenditure of muscular energy, brought about by the increased mechanization of industry and agriculture and the reduction of the hours of work, and by the rise in the proportion of the population engaged in commerce, clerical work and other quasi-sedentary occupations. Simultaneously, mechanization has increased output per head and raised the purchasing power of all classes of the population. Nor must the improvements in the methods of production and distribution of agricultural products-for example, by the widespread use of refrigeration-be left out of account.

Although the diet of most Western countries has improved very considerably during the past twenty or thirty years, and consumption habits are tending to change along the right lines, yet the report adduces evidence that, even in those countries where the improvement in dietary habits has been most marked, the diet of a substantial proportion of the population remains deficient in essential nutritive elements. Reference is made to evidences of malnutrition, when the dietary needs of different classes of the population are considered, such as expectant and nursing mothers, infants, children and adolescents, as well as adults ; whilst a special chapter at the end of the report gives statistical evidence for the statement that malnutrition still exists in countries of the most diverse social structure and stage of economic development. Such malnutrition need not result in the appearance of frank 'deficiency diseases' among the population ; in fact, the report emphasizes that, although preventive action against such diseases as scurvy, rickets and beriberi is impressive, yet it is probably of less importance to the human race than the acquisition and application of such knowledge as will also improve the general condition and well-being of every man, woman and child, through the better choice, provision and utilization of foodstuffs.

Almost half the report is devoted to the effects of changing habits of food consumption upon agriculture and the economic aspects of the question of improving nutrition, including the relationship between food prices and consumption and factors affecting the former. It is pointed out that agriculture has had no difficulty in meeting the changes in food consumption which have occurred during the past few decades, and that the adjustments necessary in the future should not be impossible, although certain difficulties exist; moreover, the change in dietary habits to which the report looks forward will be steady and gradual. Although it is likely that the demand for the protective foods will rise, yet it is considered that a considerable increase in the consumption of foods of high energy value will be required to bring the calorie content of the diet of certain sections of the population of a very large number of countries up to standards of adequacy. The increase in the demand for energy-bearing foods will more than counterbalance the decrease which accompanies an increased demand for protective foods. Also, as in the classical case of Denmark, a shift from exportation of cereals to dairying and animal husbandry need not mean a reduction in cereal cultivation; in fact, the output of cereals was increased owing to their demand for animal feed.

The obstacles in the way of adaptation of production to the new consumption trends are shown to be natural conditions, the conservatism of producers, commercial policy and penury of capital, as well as the perishable nature of many of the protective foods; wise and sympathetic consideration will overcome many of them. It is pointed out also that the contribution of agriculture to improved nutrition has not been merely adaptive only. The application of science to agriculture has produced a technical revolution parallel to, though less spectacular than, the industrial revolution. Mechanical processes have replaced hand-labour and the application of biological and chemical science has resulted in the improvement of both plants and animals or animal products used for food. Thus the breeding in Canada of Marquis wheat, which ripens early, has added 100 million acres to the potential wheat belt of Canada alone, by extending it northwards, and the annual milk yield per cow in most countries has been enormously increased. Even if, during the next five years, no further new discoveries were made but intensive national efforts were concentrated on securing the application of existing knowledge, the results on agricultural prosperity and nutritional standards would be enormous.

Turning now to the influence of food prices upon consumption, the report points out that the relationship varies in the case of different foodstuffs. Thus the demand for butter is elastic, consumption increasing markedly in recent years in countries where the price has been relatively low ; in Great Britain during the years 1923-33, whatever the price prevailing, a rise or fall in the price of butter of $1 d$. per lb. decreased or increased demand by $39,000 \mathrm{cwt}$. ; and a rise or fall in the price of cheese of $1 d$. per $1 b$. similarly decreased or increased demand by $133,000 \mathrm{cwt}$. The 'elasticity', therefore (that is, relation of proportionate change in demand to proportionate change in price) was greater when consumption was low (and prices high) than when consumption was high (and prices low). In the case of milk, the response of consumption to changes in price has been found to be fairly low ; and the same is also true of cereals. The demand for bread is inelastic, since the first 
desire of the consumer is to satisfy his hunger; and even though bread prices are kept high, bread generally still remains the cheapest way of doing this. Paying more for the bread he eats is equivalent to a reduction in the real income of the consumer, with the result that his purchases of the higher-priced protective foods are restricted, with consequent deterioration of the diet.

Evidence is adduced, in the chapter on the relation of income to nutrition, that usually the sources of 'good' protein and foods rich in minerals and vitamins are more expensive than the purely energy-bearing foods. This applies particularly to fruit, vegetables, meat, fish and eggs; while dairy products-also 'highly' protective-occupy an intermediate position. These foods, though expensive as sources of calories, are relatively cheap as sources of minerals and vitamins; their expense, however, militates against their consumption by the poorer sections of any community. With rising income, calories are purchased from more varied and expensive sources, which are usually more nutritive; thus a steady increase in the percentage of both proteins and calories derived from animal sources has been found to accompany a rising income per consumption unit. The evidence for the existence of malnutrition in many countries is supplemented by studies of the cost of adequate diets, which disclose the fact that the incomes of the poorer sections of the population are aetually insufficient to provide their members with a minimum adequate diet.

Finally, the report gives consideration to methods of improving nutrition; it insists, in the first place, that the problem must be recognized as one of primary national importance. It recommends the establishment in each country of National Nutrition Committees, containing scientific investigators, economists, agricultural experts, consumers' representatives, teachers and administrators, which would initiate investigations into the facts of nutrition, educate the consumers and make recommendations for improving the national diet. The report recommends the extension of social legislation for the protection and improvement of the health of the people, and directs attention to the value of school meals and to methods for increasing the consumption of milk. Policy must also be directed towards helping the orderly expansion of agriculture and its adaptation to the changing demand; at the same time, attention must be given to improvement of transport and distribution, with the view of reducing the margin between the price received by the producer and that paid by the consumer. Adequate nutrition must be one of the factors considered by each country in determining its economic policy.

\section{Investigation of the Upper Air}

$\mathrm{A}^{\mathrm{T}}$ T the Nottingham meeting of the British Association a discussion on the upper air which was held on the morning of September 6 was preceded by a demonstration of the ascent of a sounding balloon, organized by Prof. D. Brunt. The demonstration attracted the attention of large numbers of members of the Association, as well as of the general public. The balloon carried a Dines meteorograph, recording pressure, temperature and humidity at all stages of the ascent. The instrument was attached to the balloon by a Baker release, which consists of a small aneroid box with a catch capable of being set so that it is released from the balloon at any desired height. In the demonstration the catch was set to liberate the instruments at a height of about 12 kilometres.

The instruments were in fact released from a height of $12 \cdot 3 \mathrm{~km}$., and were found 4 miles east of Grantham and returned to Kew Observatory in good condition. The record of the meteorograph showed that the balloon had probably entered the stratosphere at a height of $12 \mathrm{~km}$., where the temperature was $-55^{\circ} \mathrm{C}$. The temperature fell steadily through the whole range of height attained, except in a layer from $\frac{1}{2}$ to $1 \mathrm{~km}$. above the ground, where it increased by about $1^{\circ} \mathrm{C}$. The record of humidity, which was probably only reliable in the lower half of the ascent, showed no features of particular interest. The general features of the temperature record agreed with those shown by the aeroplane ascent at Mildenhall on the same morning.

In the subsequent discussion in Section $\mathrm{A}$, Prof. D. Brunt explained the division of the atmosphere into troposphere and stratosphere, and explained why frequent measurements of temperature and humidity in the free air are of importance to the forecaster. The method demonstrated before the meeting has the disadvantage that days or even weeks may elapse before the record of the Dines meteorograph, or any other instrument sent up on a free balloon, is available for study. The alternative method of upper air observation which is in general use in 